\title{
Empirical Study of Dynamic Properties of Nano Oil in a Vertical Tube Simulated as A Vertical Well
}

\author{
Peyman Boustani ${ }^{1}$ and Farshad Farahbod ${ }^{2 *}$ \\ ${ }^{1}$ Department of Petroleum Engineering, Omidieh Branch, Islamic Azad University, Omidieh, Iran \\ ${ }^{2}$ Department of Chemical Engineering, Firoozabad Branch, Islamic Azad University, Firoozabad, Iran
}

Submission: December 06, 2019; Published: January 17, 2020

*Corresponding author: Farshad Farahbod, Department of Chemical Engineering, Firoozabad Branch, Islamic Azad University, Firoozabad, Iran

\begin{abstract}
The operational conditions selected in the oil industry depend on the process oil features. Being aware of the oil flow behavior in different pressures and temperatures is necessary for oil producing from different fields. The experimental show decrease trend in Reynolds number is obtained for simple oil through the $0.3 \mathrm{~m}$ length of pipe from 1276 to 1164 . For nano oil the decrease trend of Reynolds number is somehow slight from 1807 to 1789. Moreover, the decrease trend of Prandtl number is obtained for both types of nano oil and simple oil. The values of Prandtl of nano oil changes from 106 to 101 and for simple oil changes from 112 to 103. In addition, the values of peclet number for nano oil changes from 188431 to 177781 and for simple oil changes from 181034 to 166720 through the length.
\end{abstract}

Keywords: Rheology; Crude oil; Heat properties; Ultra-sonic; Nano particles

\section{Mini Review}

These days energy considered as one of the fundamental human requirements [1]. Energy taken into consideration as the vital requirement of an industry, production of foodstuffs, and agricultural productions [2]. So, that the human dependence on energy is unavoidable and that's while the major percentage of the world energy is supplied through the fossil fuels, the fuels that their utilization, unavoidably, on one hand has damages for the human health, and on the other hand has damages to the machinery and installation of the various applying industries [35]. Here it is useful to take a brief look at the types of the fossil fuels and their history [6,7]. The fossil fuels are the ones obtained from the fossils [8]. The fossil fuels are categorized to three major fuels, embodying coal, oil and natural gas [9]. All three groups started to form hundred thousand years ago even prior to appearance of the dinosaurs, the time period that these fuels started to form is the socalled "Carboniferous", which has been part of the Paleozoic period [10]. Carboniferous has taken its name from Carbon element, which is the most important constructing element of the coal and other fossil fuels $[11,12]$. The reason that they are called fossil fuels is that, in years gone by, the land was full of marshes, covered with the enormous trees, ferns, and other foliaceous plants, once the trees and plants were dying, submerged deep in the oceans and were gradually being buried, therefor the sponge shape layer, the so-called peat used to be formed [13]. After hundred years, peat was covered by sand, soil, clay, and other mineral materials and these mineral materials used to gradually convert to the sedimentary rocks [14]. The more layers accumulated, the more would be the weight, and the peat would be pressed as far as its water would be draining and after millions of years converted into the coal, oil and natural gas [15]. The different types of the cited fossil fuels have had various application levels in the daily life, work, and industry, according upon the progression level of technological knowledge and mankind capability in the exploration, exploitation, and their utilization in different times [16]. But, obviously these days the utilization of oil and gas is far more and more extensive than coal [17]. Oil also is one of the fossil fuels, which has originated three hundred million years ago, some scientists believe that the origin of oil is aquatic organisms, each one in the size of needle tip and they can act exactly like the green plants, which means convert the sun light to the stored energy in their bodies. These creatures submerge at the bottom of a sea and gradually buried under the sedimentary rocks, thereafter stones and rocks press these tiny creatures and therefore the energy in their bodies can't be exhausted, thus Carbon gradually converted to the oil through the heat and intense pressure [18]. 


\section{Materials and Methods}

The API of crude oil is about 30 . therefore, the experiments are done with medium crude oil. Moreover, the Ferric dioxide $\left(\mathrm{Fe}_{2} \mathrm{O}_{3}\right)$ is a transition metal oxide that has long been known to be active for hydrocarbon decomposition and has more recently shown to display high reforming activity for various long-chain Hydrocarbons. Researches showed that $\mathrm{Fe}_{2} \mathrm{O}_{3}$ is highly active for reforming isooctane via partial oxidation.

\section{Experimental setup}

The experimental set up includes mixing tank, adiabatic tube test section and electrical heater is used to survey the behavior of nano crude oil.

\section{Investigation of rheology of stream}

There are different methods and equipment for measuring the rheological properties of a fluid. For crude oil the most common way is by using a Fann 35 Viscometer.

\section{Experimental correlations for calculating of heat transfer}

The laboratory measurements have usually determined the relationship for heat transfer between a flowing fluid and a solid surface.

\section{Results and Discussion}

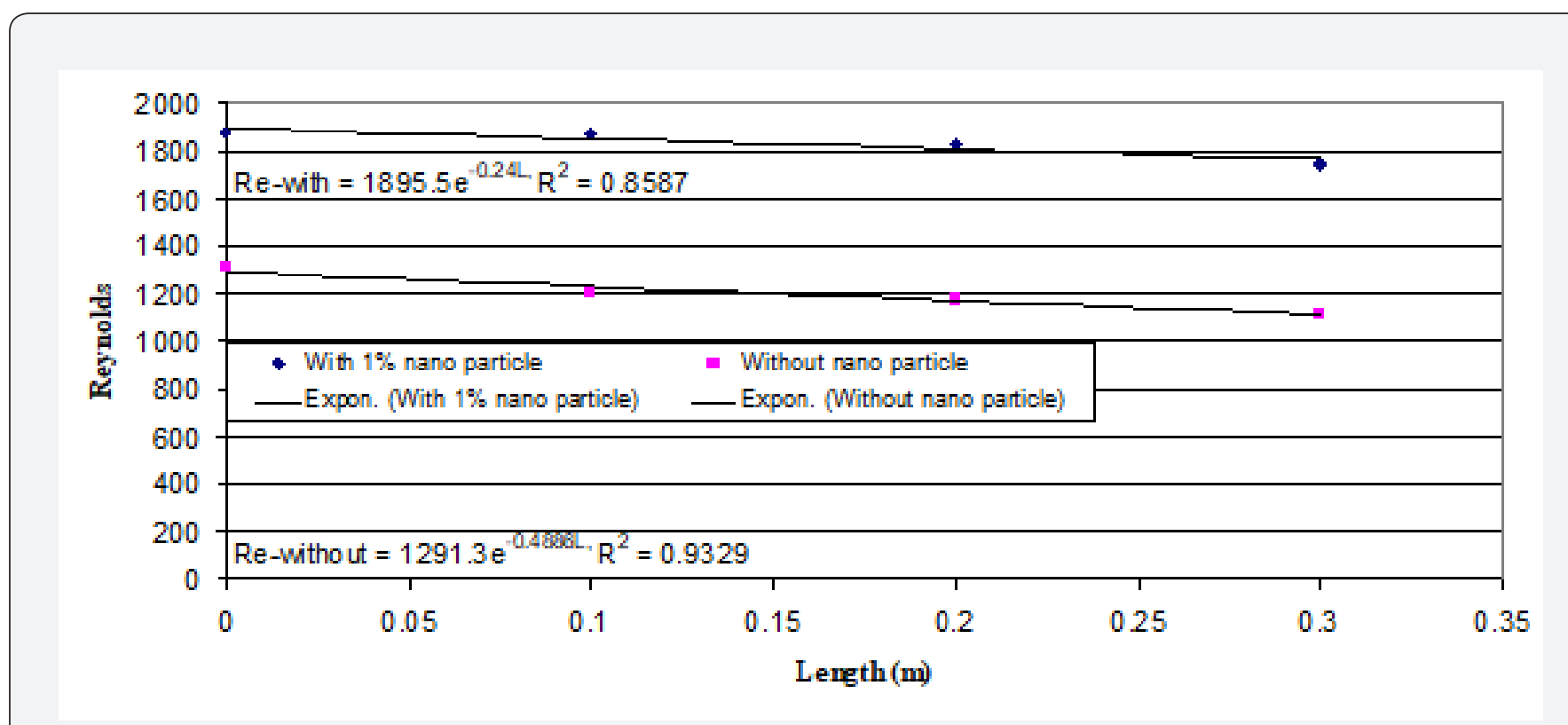

Figure 1: Values of Reynolds Number through the Length.

The obtained results are shown in this section. The (Figures 1-4) illustrate the rheology of nano oil in the vertical tube. Reynolds number is one of the important dimensionless numbers which is used extensively in hydrodynamic field. The total effect of nano ferric oxide on the velocity, viscosity and density of oil through the length is shown in the Figure 1. The decrease trend in Reynolds number is obtained for simple oil through the $0.3 \mathrm{~m}$ length of pipe from 1276 to 1164 . For nano oil the decrease trend of Reynolds number is somehow slight from 1807 to 1789. Evaluation of thermo-physical properties of the fluid is easier with Prandtl number to calculate heat transfer properties. Figure 2 shows the changes of Prandtl number versus length. The decrease trend of Prandtl number is obtained for both types of nano oil and simple oil. The values of Prandtl of nano oil changes from 106 to 101 and for simple oil changes from 112 to 103 . The Figure 3 shows the values of peclet number of nano oil and simple oil through the length. Values of peclet number for nano oil changes from 188431 to 177781 and for simple oil changes from 181034 to 166720 through the length. Values of Stanton number versus length of tubes is shown in the Figure 4. The increasing trend is obtained for both simple oil and nano oil. Values of Stanton change from $1.77 \times 10^{+3}$ to $1.87 \times 10+3$ for simple oil and from $1.8 \times 10+3$ to $1.99 \times 10^{+3}$ for nano oil. 


\section{Trends in Technical \& Scientific Research}

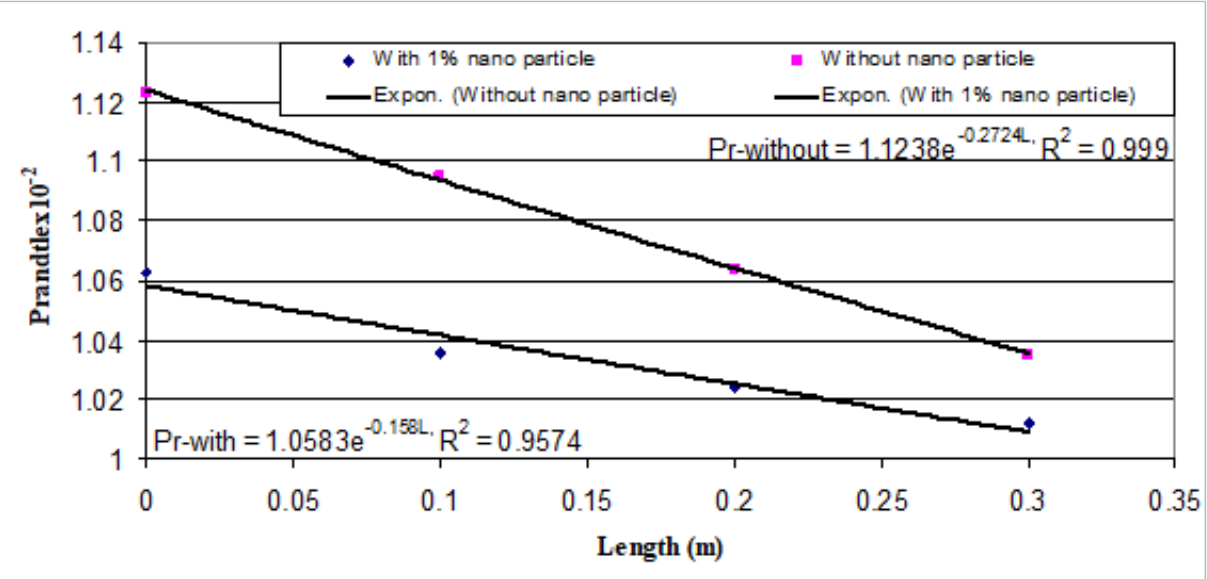

Figure 2: Prandtl Number versus Length.

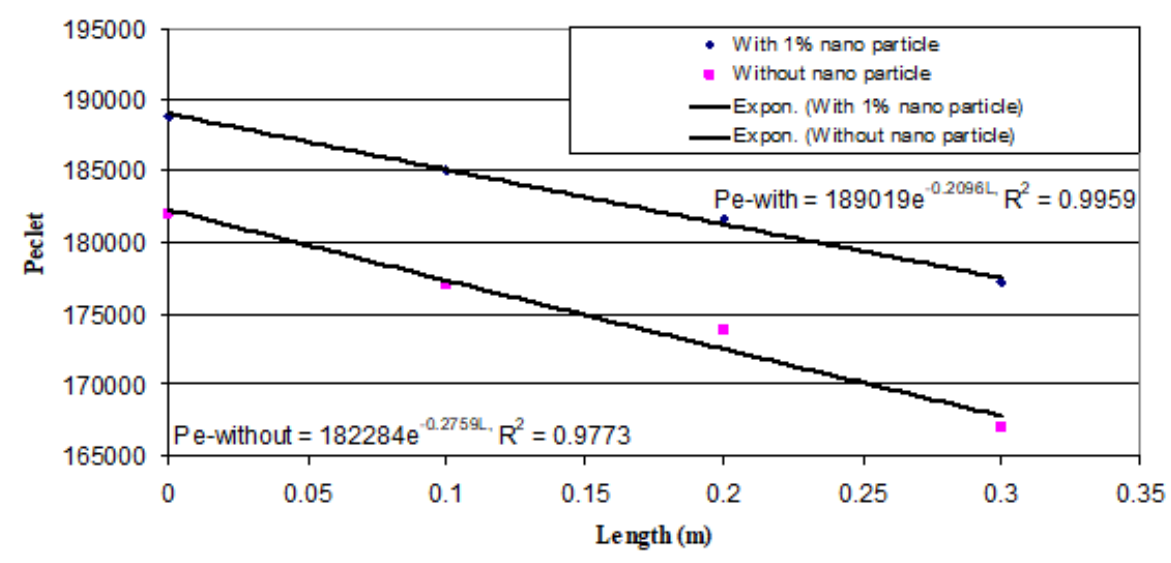

Figure 3: Peclet Number versus Length.

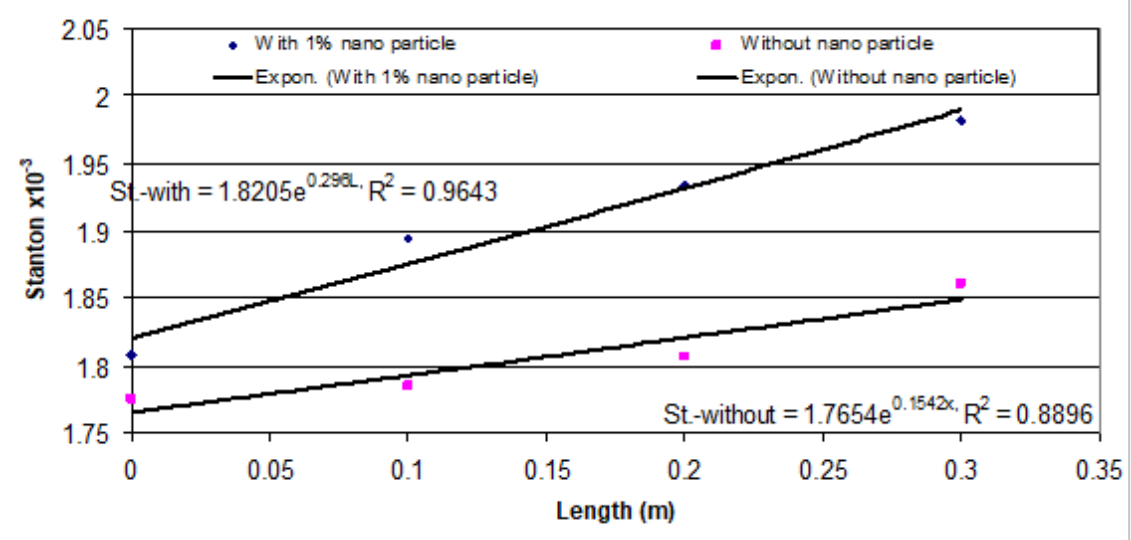

Figure 4: Stanton Number Values versus Tube Length. 


\section{Conclusion}

The operational conditions selected in the oil industry depend on the process oil features. Being aware of the oil flow behavior in different pressures and temperatures is necessary for oil producing from different fields. Application of nano ferric oxide in oil is studied in this manuscript. The effect of addition of different weight percentage of nano particle into the oil which flows vertically under different temperatures (ranges from $30-70^{\circ} \mathrm{C}, 25-$ $85^{\circ} \mathrm{C}, 30-90^{\circ} \mathrm{C}$ ) in a tube section is investigated, experimentally. The experimental show decrease trend in Reynolds number is obtained for simple oil through the $0.3 \mathrm{~m}$ length of pipe from 1276 to 1164 . For nano oil the decrease trend of Reynolds number is somehow slight from 1807 to 1789 . Moreover, the decrease trend of Prandtl number is obtained for both types of nano oil and simple oil. The values of Prandtl of nano oil changes from 106 to 101 and for simple oil changes from 112 to 103. In addition, the values of peclet number for nano oil changes from 188431 to 177781 and for simple oil changes from 181034 to 166720 through the length. Also, the increasing trend is obtained for both simple oil and nano oil. Values of Stanton change from $1.77 \times 10^{+3}$ to $1.87 \times 10^{+3}$ for simple oil and from $1.8 \times 10^{+3}$ to $1.99 \times 10^{+3}$ for nano oil.

\section{References}

1. Storm DA, McKeon RJ, McKinzie HL, Redus CL (1999) Drag Reduction in Heavy Oil. J Energy Resour Technol 121(3): 145-148.

2. Rached BM, Pervez A, Habib MA (2015) Simulation of Oxy-fuel combustion of heavy oil fuel in a model furnace. J Energy Resour Technol 137(3): 032206.

3. Shadi WH, Mamdouh TG, Nabil E (2010) Heavy crude oil viscosity reduction and rheology for pipeline transportation. Fuel 89(5): 10951100.

4. Martnez PR, Mosqueira ML, Zapata RB, Mar JE, Bernal HC, et al. (2011) Transportation of heavy and extra-heavy crude oil by pipeline: a review. J Pet Sci Eng 75(3-4): 274-282.

5. Elphingstone GM, Greenhill KL, Hsu JJC (1999) Modeling of Multiphase Wax Deposition. J Energy Resour Technol 121(2): 81-85.
6. Weissman JG (1997) Review of processes for downhole catalytic upgrading of heavy crude oil. Fuel Proc Technol 50(2-3): 199-213.

7. Rana MS, Stomano V, Ancheyta J, Diaz JAI (2007) A review of recent advances on process technologies for upgrading of heavy oils and residua. Fuel 86(9): 1216-1231.

8. Naseri A, Nikazar M, Mousavi DSA (2005) A correlation approach for prediction of crude oil viscosities. J Pet Sci Eng 47(3-4): 163-174.

9. Hossain MS, Sarica C, Zhang HQ (2005) Assessment and development of heavy-oil viscosity correlations. In: SPE International Thermal Operations and Heavy Oil Symposium, Kalgary, p. 1-9.

10. Alomair 0, Elsharkawy A, Alkandari H (2011) Viscosity prediction of Kuwaiti heavy crudes at elevated temperatures. In: SPE Heavy Oil Conference and Exhibition, Kuwait, p. 1-18.

11. Yigit AS, Christoforou AP (2006) Stick-Slip and Bit-Bounce Interaction in oil-well Drillstrings. J Energy Resour Technol 128(4): 268-274.

12. Barrufet MA, Setiadarma A (2003) Reliable heavy oil-solvent viscosity mixing rules for viscosities up to $450 \mathrm{~K}$, oil-solvent viscosity ratios up to $4 \times 10^{5}$, and any solvent proportion. Fluid Phase Equilib 213(1-2): 65-79.

13. Luis FA, Doruk A (2008) Evaluation of "Marching Algorithms" in the Analysis of Multiphase Flow in Natural Gas Pipelines. J Energy Resour Technol 130(4): 043003.

14. Yilin WJ (2011) Well Completion for Effective Deliquification of Natural Gas wells. J Energy Resour Technol 134(1): 013102.

15. Chuan L, Huiqing L, Qiang Z, Qingbang M (2014) Experimental Study of Reasonable Drawdown Pressure of Horizontal Wells in Oil Reservoir with Bottom Water. J Energy Resour Technol 136(3): 034502.

16. Junlai W, Yuetian L, Haining Y (2012) New Method of Productivity Equation for Multibranch Horizontal Well in Three-Dimensional Anisotropic Oil Reservoirs. J Energy Resour Technol 134(3): 032801032801, p. 1-5.

17. Anuj G (2012) Performance Optimization of Abrasive Fluid Jet for Completion and Stimulation of Oil and Gas Wells. J Energy Resour Technol 134(2): 021001.

18. Bhuwakietkumjohn N, Rittidech S (2010) Internal flow patterns on heat transfer characteristics of a closed-loop oscillating heat-pipe with check valves using ethanol and a silver nano-ethanol mixture. Exp Therm Fluid Sci 34(8): 1000-1007.

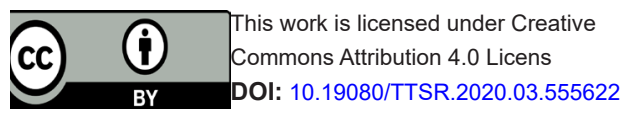

Your next submission with Juniper Publishers will reach you the below assets

- Quality Editorial service

- Swift Peer Review

- Reprints availability

- E-prints Service

- Manuscript Podcast for convenient understanding

- Global attainment for your research

- Manuscript accessibility in different formats

( Pdf, E-pub, Full Text, Audio)

- Unceasing customer service

Track the below URL for one-step submission https://juniperpublishers.com/online-submission.php 